ARTICLE

\title{
Controlling hot electron flux and catalytic selectivity with nanoscale metal-oxide interfaces
}

Si Woo Lee (1) 1,2,7, Jong Min Kim³,4, Woonghyeon Park ${ }^{5,7}$, Hyosun Lee ${ }^{1,6}$, Gyu Rac Lee ${ }^{3}$, Yousung Jung (D) ${ }^{5 凶}$, Yeon Sik Jung (i) ${ }^{3 凶} \&$ Jeong Young Park (iD ${ }^{1,2 凶}$

Interaction between metal and oxides is an important molecular-level factor that influences the selectivity of a desirable reaction. Therefore, designing a heterogeneous catalyst where metal-oxide interfaces are well-formed is important for understanding selectivity and surface electronic excitation at the interface. Here, we utilized a nanoscale catalytic Schottky diode from $\mathrm{Pt}$ nanowire arrays on $\mathrm{TiO}_{2}$ that forms a nanoscale $\mathrm{Pt}-\mathrm{TiO}_{2}$ interface to determine the influence of the metal-oxide interface on catalytic selectivity, thereby affecting hot electron excitation; this demonstrated the real-time detection of hot electron flow generated under an exothermic methanol oxidation reaction. The selectivity to methyl formate and hot electron generation was obtained on nanoscale Pt nanowires $/ \mathrm{TiO}_{2}$, which exhibited $\sim 2$ times higher partial oxidation selectivity and $\sim 3$ times higher chemicurrent yield compared to a diode based on $\mathrm{Pt}$ film. By utilizing various $\mathrm{Pt} / \mathrm{TiO}_{2}$ nanostructures, we found that the ratio of interface to metal sites significantly affects the selectivity, thereby enhancing chemicurrent yield in methanol oxidation. Density function theory (DFT) calculations show that formation of the $\mathrm{Pt}-\mathrm{TiO}_{2}$ interface showed that selectivity to methyl formate formation was much larger in Pt nanowire arrays than in Pt films because of the different reaction mechanism.

\footnotetext{
${ }^{1}$ Center for Nanomaterials and Chemical Reactions, Institute for Basic Science (IBS), Daejeon 34141, Republic of Korea. ${ }^{2}$ Department of Chemistry, Korea Advanced Institute of Science and Technology (KAIST), Daejeon 34141, Republic of Korea. ${ }^{3}$ Department of Materials Science and Engineering, Korea Advanced Institute of Science and Technology (KAIST), Daejeon 34141, Republic of Korea. ${ }^{4}$ Materials Architecturing Research Center, Korea Institute of Science and Technology (KIST), Seoul 02792, Republic of Korea. ${ }^{5}$ Department of Chemical and Biomolecular Engineering, Korea Advanced Institute of Science and Technology (KAIST), Daejeon 34141, Republic of Korea. ${ }^{6}$ Present address: Korea Institute of Industrial Technology (KITECH), Intelligent Sustainable Material R\&D Group, Cheonan 31056, Republic of Korea. ${ }^{7}$ These authors contributed equally: Si Woo Lee, Jong Min Kim, Woonghyeon Park.

凶email: ysjn@kaist.ac.kr; ysjung@kaist.ac.kr; jeongypark@kaist.ac.kr
} 
nderstanding the mechanisms of energy dissipation and electronic excitation at solid-gas interfaces on heterogeneous catalyst is important for various energy conversion applications to improve energy efficiency ${ }^{1-4}$. In particular, through exothermic catalytic reactions on a metal catalyst surface, non-adiabatic energy dissipation leads to the flow of energetic electrons with an energy of $1-3 \mathrm{eV}$ (i.e., reaction-induced hot electrons) from a chemical energy conversion process; this flow of electrons operates on a femtosecond time scale before atomic vibrations dissipate the energy by adiabatic process ${ }^{5-9}$. However, because of the extremely short lifetime by thermalization (i.e., within a few femtoseconds via electron-electron or electronphonon scattering) and mean free path of hot electrons in metal catalysts, directly detecting catalytically excited hot electrons before relaxation has been challenging ${ }^{3,8,10}$. Recently, metalsemiconductor Schottky nanodiodes, composed of a metal catalyst film deposited on a semiconductor substrate, have emerged as a powerful strategy for quantitative real-time detection of hot electron transfer excited on catalyst surface by exothermic chemical reactions ${ }^{11-13}$. When the potential barrier formed at the metal-semiconductor junctions (i.e., the Schottky barrier) is lower than the energy of the chemically excited electrons $(1-3 \mathrm{eV})$ by catalytic reaction, the Schottky barrier allows excited hot electrons to irreversibly transport through the metal-semiconductor junction. Once hot electrons arrive at the semiconductor by transfer, these electrons cannot go back to the metal catalyst, leading to the irreversible and one-way hot electron transfer from the metal catalyst to the semiconductor. Therefore, metalsemiconductor catalytic nanodiodes allow the quick capture of energetic hot electrons before thermalization; the detected current is known as chemicurrent $5,9,14$.

In heterogeneous catalysis, one of the key strategies for enhancing the reaction rate and selectivity is the use of catalytically active metal nanoparticles supported on an oxide support, forming a metal-oxide interface ${ }^{15-17}$. Strong metal-support interaction (SMSI) effect, in which the encapsulation of metal nanoparticles by reducible oxide-support overlayers can affect the catalytic behavior of metal nanoparticles (i.e., migration of oxide support onto the active metal surface) was discovered by Tauster et al. ${ }^{18,19}$. Matsubu et al. ${ }^{20}$ also showed that adsorbatefunctionalized encapsulation of metal nanoparticles by the reducible oxide support (e.g., $\mathrm{TiO}_{2}$ and $\mathrm{Nb}_{2} \mathrm{O}_{5}$ ) can influence the selectivity of $\mathrm{CO}_{2}$ hydrogenation in heterogeneous $\mathrm{Rh}$ catalysts (i.e., adsorbate-mediated SMSI effect) and these results were proved by observing changes in pre-treatment through in situ diffuse-reflectance infrared Fourier transform spectroscopy and in situ scanning transmission electron microscopy $(\mathrm{TEM})^{20}$. Studies of low-temperature CO oxidation on gold nanoparticles on $\mathrm{TiO}_{2}$ support catalyst exhibits that the metal-oxide interface along its perimeter can dramatically change the catalytic activity $^{21,22}$. Therefore, it can be seen that the formation of metaloxide interface in heterogeneous catalyst plays an important role in altering the catalytic reaction.

In contrast to one-path reactions such as $\mathrm{CO}$ or hydrogen oxidation, the research on selectivity for achieving the desired product molecule in multi-path reactions is a challenging issue; this is the ultimate goal of a heterogeneous catalyst for green chemistry $4,20,23-25$. Among the various multi-path reactions, the gas-phase methanol oxidation reaction, which produces $\mathrm{CO}_{2}$ and methyl formate by full oxidation and partial oxidation of methanol, is an important transformation process for the conversion of energy and chemical synthesis ${ }^{26}$. The partial oxidation of methanol to methyl formate is an especially efficient and environmentally benign way of producing valuable chemicals. Furthermore, it has been demonstrated that the oxidation state or chemical composition of the metal catalyst can affect the selectivity to methyl formate under methanol oxidation ${ }^{27-29}$. Recently, it was found that the quantity of hot electrons generated in the methanol oxidation reaction is affected by the selectivity of methyl formate production using a $\mathrm{Pt}$ film/ $/ \mathrm{TiO}_{2}$ catalytic nanodiode $^{30}$. In addition, previous studies have revealed that the partial oxidation of methanol increases when the metal-oxide interfacial sites (i.e., $\mathrm{Pt} / \mathrm{FeO}$ and $\mathrm{Au} / \mathrm{TiO}_{2}$ ) are formed by using theoretical calculation and surface science techniques 31,32 . Therefore, the smart design of heterogeneous catalysts can improve the selectivity of metal catalysts on reducible oxide supports (e.g., Pt nanoparticles or nanowires on oxide support substrate) by engineering the metal-oxide interface ${ }^{8}$.

In this study, to demonstrate the effect of metal-oxide interface on selectivity and reaction-induced hot electrons (i.e., chemicurrent), we fabricated a Schottky nanodiode with Pt nanowires on $\mathrm{TiO}_{2}$ support forming nanoscale $\mathrm{Pt}-\mathrm{TiO}_{2}$ interface that was exposed on the gas-phase reaction environment. Using the fabricated $\mathrm{Pt}$ nanowires $/ \mathrm{TiO}_{2}$ catalytic nanodiode, we report the in situ detection of charge flow as steady-state chemicurrent generated by gas-phase catalytic methanol oxidation on the $\mathrm{Pt}$ nanowire catalysts supported on $\mathrm{TiO}_{2}$. To find the dynamics of reaction-induced hot electrons on the metal-oxide interface, the results of partial oxidation selectivity and chemicurrent on $\mathrm{Pt}$ nanowires $/ \mathrm{TiO}_{2}$ were compared with the results of the Pt film/ $\mathrm{TiO}_{2}$ Schottky nanodiode whose metal-oxide interface was not exposed to the environment of the gas-phase chemical reaction. We showed that formed nanoscale $\mathrm{Pt}-\mathrm{TiO}_{2}$ interface gives rise to the higher selectivity of methyl formate, thereby hot electrons were excited much more on the $\mathrm{Pt}-\mathrm{TiO}_{2}$ interface, as the hot electron generation was affected by selectivity under methanol oxidation. Comparing the simulation results by density functional theory (DFT) from the two models of Pt nanorod on $\mathrm{TiO}_{2}(110)$ and $\mathrm{Pt}(111)$, we could support the increase in selectivity at the Pt$\mathrm{TiO}_{2}$ interface due to the difference of activation barrier.

\section{Results}

Detection of hot electrons on $\mathrm{Pt}$ nanowires/ $\mathrm{TiO}_{2}$ nanodiodes. The metal-oxide interface was fabricated on the catalytic Schottky nanodiodes by depositing the two-dimensional $\mathrm{Pt}$ nanowire arrays on the surface of $\mathrm{TiO}_{2}$ using lithography, thus creating a well-defined nanoscale interface between the platinum and the titanium dioxide. A previous study on lithographically fabricated Pt nanowire arrays on oxide support found strong oxide support dependence for both TOF and the activation energy of the CO oxidation reaction ${ }^{33,34}$. Thus, in this study, the $\mathrm{Pt}$ nanowire arrays were chosen to form the metal-oxide interface, because these nanowires can be deposited on the $\mathrm{TiO}_{2}$, while sustaining the electrical connection for the fabrication of Schottky nanodevices when exposing the well-defined $\mathrm{Pt}_{-} \mathrm{TiO}_{2}$ interface to the reaction environment. A scheme of the fabricated catalytic nanodiode is presented in Fig. 1a, where the two-dimensional Pt nanowire arrays were deposited on the thin-film $\mathrm{TiO}_{2}$ surface, forming a $\mathrm{Pt}$ nanowires $/ \mathrm{TiO}_{2}$ catalytic nanodiode. The figure in the inset shows that methanol oxidation occurs at the metal-oxide interface formed by the deposition of $\mathrm{Pt}$ nanowires on $\mathrm{a} \mathrm{TiO}_{2}$ surface. The Schottky nanodevice was well-constructed, the width of the Pt nanowires was $20 \mathrm{~nm}$, and the pitch of the nanowire arrays was $50 \mathrm{~nm}$, as shown in scanning electron microscopy (SEM) image.

The energy band diagram for real-time detection of hot electron flux as steady-state chemicurrent under methanol oxidation on $\mathrm{Pt}$ nanowires $/ \mathrm{TiO}_{2}$ catalytic nanodiode is illustrated in Fig. 1b. Here, a $\mathrm{Au} / \mathrm{Ti}$ film layer for the ohmic contact electrodes of the nanodiodes on both sides is deposited by electron beam evaporation. As a probe reaction, methanol oxidation showing two reaction products 

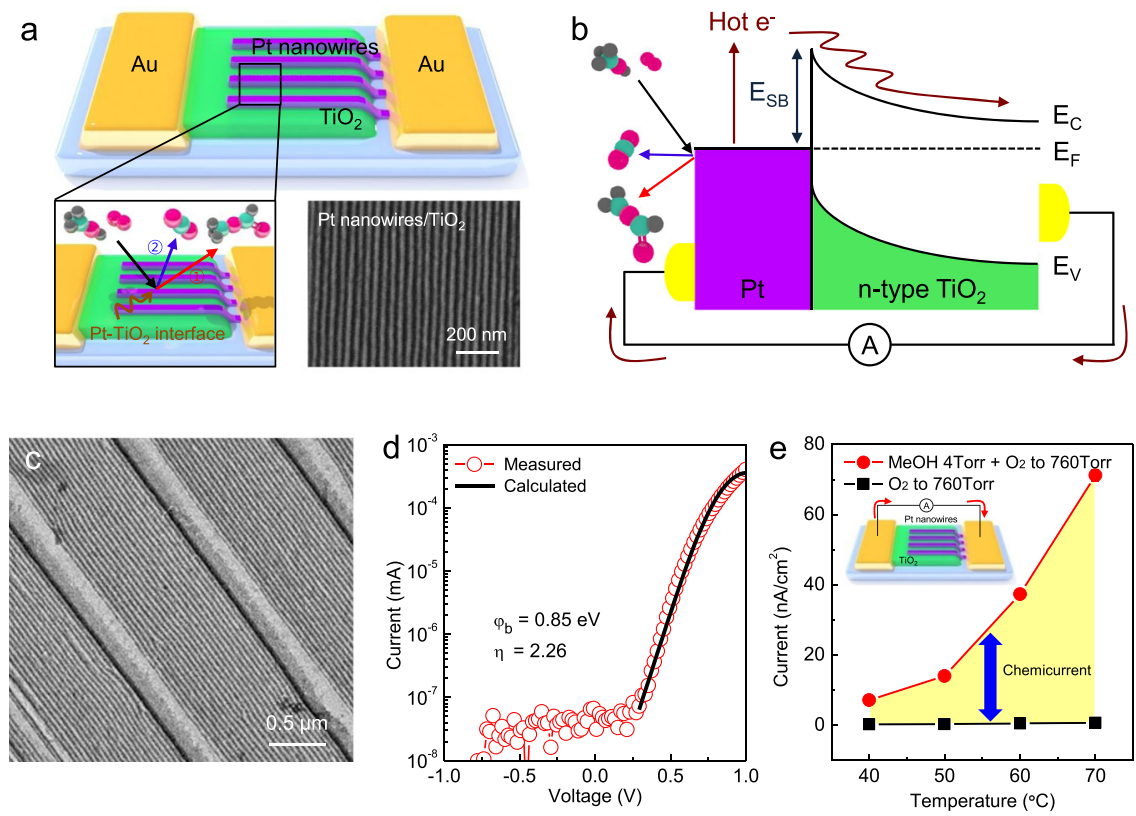

Fig. 1 Detection of hot electrons generated on $\mathrm{Pt}$ nanowires/ $/ \mathrm{TiO}_{2}$ nanodiode. a Schematic of hot electron generation on the $\mathrm{Pt}$ nanowires/TiO 2 catalytic nanodiode during exothermic methanol oxidation. Methanol oxidation occurs, and $\mathrm{CO}_{2}$ and methyl formate are produced at the $\mathrm{Pt}-\mathrm{TiO} \mathrm{O}_{2}$ interface formed by the bonding of $\mathrm{Pt}$ nanowires and $\mathrm{TiO}_{2}$. In this process, non-adiabatic energy dissipation occurs and hot electrons are generated on the nanodiode surface. SEM image of Pt nanowire arrays with a width of $20 \mathrm{~nm}$ and a pitch of $50 \mathrm{~nm}$. $\mathbf{b}$ Energy band diagram for Schottky nanodiode of the Pt nanowires supported on $\mathrm{TiO}_{2}$. Hot electrons excited from the surface chemical reaction can be detected as a steady-state chemicurrent by charge transfer if their excess chemical energy is large enough to overcome the Schottky barrier of the $\mathrm{Pt}_{-} \mathrm{TiO}_{2}$ junction. c TEM image of the transferred $\mathrm{Pt}$ nanowire arrays on TEM grid with a width of $20 \mathrm{~nm}$. d Current-voltage $(I-V)$ curves for the Pt nanowires $/ \mathrm{TiO}_{2}$ catalytic nanodiode. The solid line is a fit of the obtained $I-V$ curve to the thermionic emission theory. The obtained Schottky barrier height was $0.85 \mathrm{eV}$. e Current density associated with the methanol oxidation measured on the Pt nanowires $/ \mathrm{TiO}_{2}$ with increased reaction temperature. The differences in the magnitude of the currents measured with and without catalytic reaction were associated with reaction-induced hot electrons generated on the catalytic nanodiode (i.e., net chemicurrent).

(i.e., $\mathrm{CO}_{2}$ and methyl formate production by full oxidation and partial oxidation of methanol reactant, respectively) was chosen, as it is an exothermic reaction with low temperature that is stable for maintaining the electrical properties of the catalytic nanodiode. When methanol oxidation, as an exothermic catalytic reaction, occurs in the catalyst, hot electrons were generated by nonadiabatic electronic excitation (i.e., chemical energy conversion) and only energetic electrons can be detected through the Schottky barrier formed at the metal-semiconductor junction as the electric current (i.e., chemical reaction-induced current flow).

To characterize the microstructure of Pt nanowires using TEM, the fabricated Pt nanowires were directly transferred onto a TEM grid in the same way that they were transferred to the nanodiodes for TEM sampling, as shown in Fig. 1c. Larger Pt nanowires with a width of $200 \mathrm{~nm}$ were observed between smaller Pt nanowires with a width of $20 \mathrm{~nm}$. The formation of larger Pt nanowires was influenced by the topographical template required to control the long-range order of self-assembled block copolymer patterns ${ }^{35,36}$. Thus, we confirmed that the fabricated catalytic nanodiode was well designed, and that the junction formed between the $\mathrm{Pt}$ nanowire arrays and $\mathrm{TiO}_{2}$ was stable.

To investigate the electrical properties and rectifying behavior of the fabricated $\mathrm{Pt}$ nanowires/ $\mathrm{TiO}_{2}$ catalytic nanodiode, current-voltage $(I-V)$ curves were plotted. As shown in Fig. 1d, by fitting the $I-V$ curve of the nanodiode to the thermionic emission equation, a Schottky barrier of $0.85 \mathrm{eV}$ was obtained, which was similar to that of the device based on Pt film (see Supplementary Note 1 for details). Thus, the effect of Schottky barrier height on the hot electron detection can be excluded by showing a similar Schottky barrier to that of the Pt film (i.e., about 0.87 and $0.85 \mathrm{eV}$ for Pt film $/ \mathrm{TiO}_{2}$ and Pt nanowires/TiO respectively). Recently, the detection of excited hot electrons as a steady-state chemicurrent under the catalytic oxidation of $\mathrm{CO}$ or hydrogen was demonstrated by using metal catalyst/TiO Schottky nanodiodes and a clear correlation was found between catalytic activity and reaction-induced hot electron flux ${ }^{10,37-41}$. In this study, the chemically excited hot electrons generated by methanol oxidation were enough to irreversibly overcome the Schottky barrier at the Pt nanowire arrays/ $/ \mathrm{TiO}_{2}$ junction when the excess chemical energy was higher than the Schottky barrier height of the nanodiode (i.e., obtained sufficient energy) and could be detected as a current of hot electron flow.

The fabrication procedure of patterned Pt nanowire arrays on a $\mathrm{TiO}_{2}$ support with self-assembled block copolymer is shown in Supplementary Fig. 1. Bulk Au nanowires, 200 nm, were printed on the Pt nanowires to prevent electrical shorts from defects in the Pt nanowires (Supplementary Fig. 2a). As the bulk $\mathrm{Au}$ nanowires were much larger than the Pt nanowire arrays, the $\mathrm{Au}$ nanowire arrays had no effect on the catalytic reaction. Moreover, X-ray photoelectron spectroscopy (XPS) was used to demonstrate the chemical composition of $\mathrm{Pt}$ nanowires on $\mathrm{TiO}_{2}$, showing that the oxidation state was maintained in a metallic state (Supplementary Fig. 2b). In addition, X-ray diffraction (XRD) patterns of the Pt nanowires deposited on silicon wafer exhibited the polycrystalline nature of the transferred Pt nanowires (Supplementary Fig. 2c). To demonstrate the area density effect of the metal-oxide interface, nanodiodes were fabricated by depositing Pt nanowire arrays with widths of 15,20 , and $50 \mathrm{~nm}$ on a $\mathrm{TiO}_{2}$ support; the morphology of these deposited Pt nanowire arrays and Pt film was confirmed by SEM (Supplementary Fig. 3a-d).

We monitored the electric current signals flowing across the Pt nanowires $/ \mathrm{TiO}_{2}$ Schottky contact at the open circuit by ammeter 
during reaction conditions (methanol 1-4 Torr and $\mathrm{O}_{2}$ to 760 Torr) and non-reactive conditions (pure $\mathrm{O}_{2} 760$ Torr) at elevated temperatures. The stable steady-state current signals on a $\mathrm{Pt}$ nanowires/ $/ \mathrm{TiO}_{2}$ Schottky nanodiode by catalytic methanol oxidation with elevated reaction temperatures are shown in Fig. 1e, where the measured electric current increased as the reaction activity increased with rising temperature. Under a pure oxygen environment (760 Torr of $\mathrm{O}_{2}$ ), there was a weak thermoelectric current caused by the difference in electrical potential between the two electrodes (i.e., Seebeck effect) ${ }^{41}$. A definite deviation between the currents measured with and without catalytic reaction was observed and the difference in magnitude of the currents was clearly associated with hot electron generation from the catalytic methanol oxidation on the $\mathrm{Pt}-\mathrm{TiO}_{2}$ interface. Therefore, this result suggests that chemicurrent measurement by using the $\mathrm{Pt}$ nanowires $/ \mathrm{TiO}_{2}$ catalytic nanodiodes can indeed be used to monitor the surface chemical reaction at the metal-oxide interface in a quantitative and sensitive manner. Pt nanowires $/ \mathrm{TiO}_{2}$ catalytic nanodiodes exhibit good thermal stability, showing a stable steadystate chemicurrent due to electrical stability under oxygen-rich conditions (see Supplementary Note 2 and Supplementary Figs. 47 for details).

Effect of metal-oxide interface on selectivity. Recently, it was observed that selectivity of partial oxidation in the methanol oxidation reaction exhibited a significant increase when the Pt$\mathrm{TiO}_{2}$ interface was formed, which was well supported by theoretical calculations ${ }^{42,43}$. Thus, in this study, to find the metaloxide interface effect on selectivity and reaction-induced hot electron, the results of $\mathrm{Pt}$ nanowire/ $/ \mathrm{TiO}_{2}$ were compared with a $\mathrm{Pt}$ film $/ \mathrm{TiO}_{2}$ without an exposed metal-oxide interface.
We calculated turnover frequency (TOF) for $\mathrm{CO}_{2}$ and methyl formate production from the slope of the turnover number with reaction time carried out in a batch reactor system (Supplementary Fig. 8a). The selectivity to methyl formate formation was then calculated from the ratio of formation rate of methyl formate to $\mathrm{CO}_{2}$; the selectivity to produce methyl formate decreases with increasing temperature, which is similar to the tendency in our previous results of $\mathrm{Pt}$ film/ $/ \mathrm{TiO}_{2}$ catalytic nanodiode (Supplementary Fig. 8b). The decline of selectivity with rising temperature was a result of the higher activation energy for full oxidation pathway than partial oxidation ${ }^{26}$. All TOF and selectivity were obtained in methanol conversion of less than $10 \%$. As shown in Fig. 2a, the total TOF value (i.e., the sum of the TOFs of $\mathrm{CO}_{2}$ and methyl formate production) was similar for $\mathrm{Pt}$ nanowires $/ \mathrm{TiO}_{2}$ and $\mathrm{Pt}$ film $/ \mathrm{TiO}_{2}$. Through this, it can be seen that the $\mathrm{Pt}-\mathrm{TiO}_{2}$ interface formed from $\mathrm{Pt}$ nanowires/ $/ \mathrm{TiO}_{2}$ does not affect the total reactivity. Unlike the TOF results, surprisingly, Pt nanowires/ $\mathrm{TiO}_{2}$ showed much higher selectivity toward methyl formate formation than $\mathrm{Pt}$ film $/ \mathrm{TiO}_{2}$; these results clearly indicate that the $\mathrm{Pt}-\mathrm{TiO}_{2}$ interface affects the selectivity of the chemical reaction, which is similar to previously reported results (Fig. 2b) ${ }^{43}$. Therefore, this indicates that when the $\mathrm{Pt}-\mathrm{TiO}_{2}$ interface was formed, $\mathrm{CO}_{2}$ production was reduced and methyl formate production was increased, resulting in significant increase in selectivity, whereas total TOF was similar in both systems; thus, it can be said that $\mathrm{Pt}$ nanowires/ $/ \mathrm{TiO}_{2}$ was a more efficient catalyst for selective reaction producing methyl formate than $\mathrm{Pt}$ film $/ \mathrm{TiO}_{2}$. All the TOF values obtained from Pt film/ $/ \mathrm{TiO}_{2}$ and Pt nanowires/ $\mathrm{TiO}_{2}$, and the calculated selectivity are shown in Supplementary Tables 1 and 2, respectively. There have been previous studies to increase catalytic performance by increasing coverage degree of
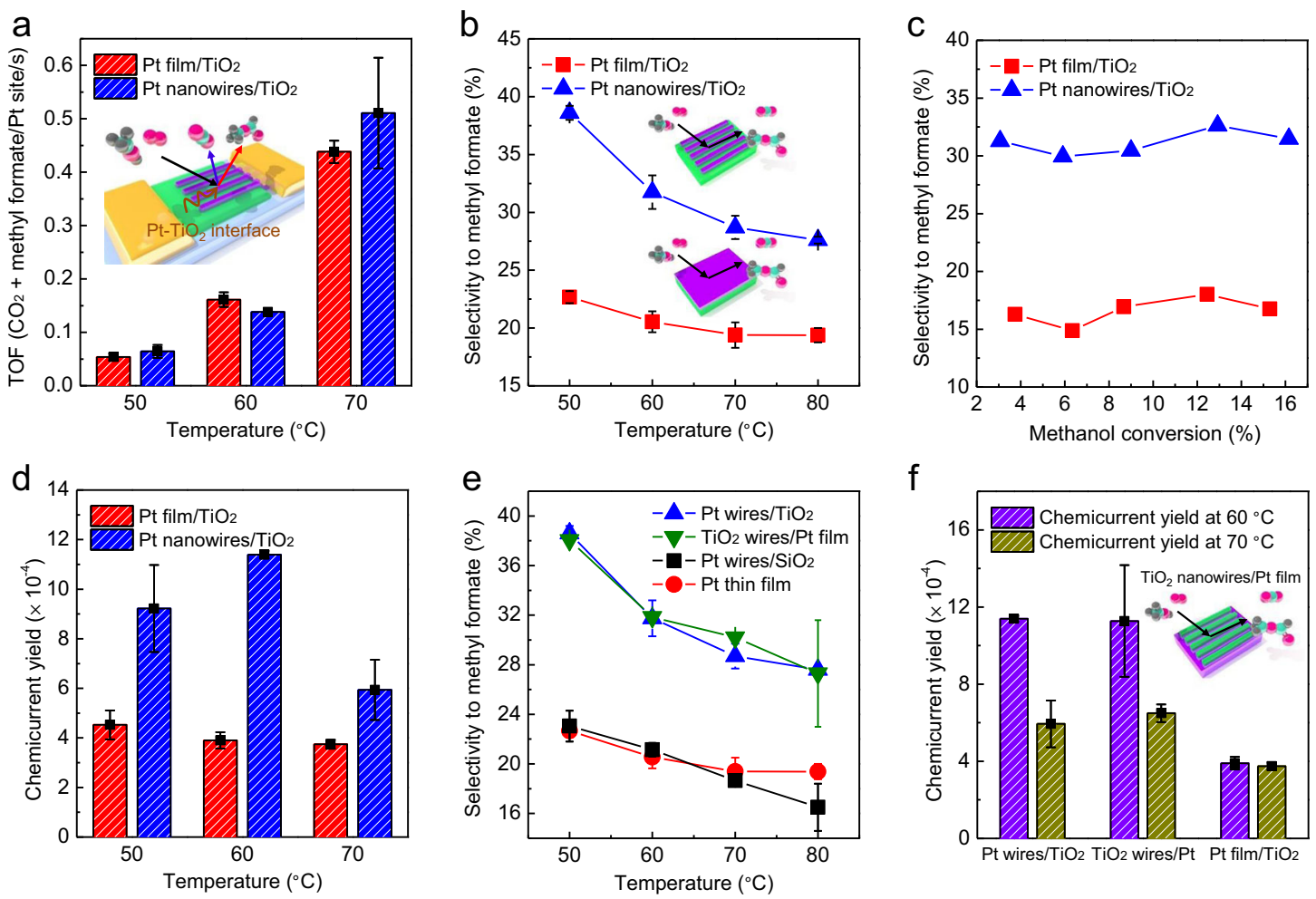

Fig. 2 Selectivity and hot electron generation on nanodiodes. Comparison of $\mathbf{a}$ total reactivity and $\mathbf{b}$ partial oxidation selectivity under methanol oxidation for two Schottky nanodiodes of Pt film and Pt nanowires supported on $\mathrm{TiO}_{2}$ at different temperatures. $\mathbf{c}$ Plot of selectivity according to methanol conversion on the catalytic nanodiodes of $\mathrm{Pt}$ film $/ \mathrm{TiO}_{2}$ and $\mathrm{Pt}$ nanowires $/ \mathrm{TiO}_{2}$ measured at $343 \mathrm{~K}$. $\mathbf{d}$ Chemicurrent yield associated with the efficiency for hot electron flow obtained from the Pt film $/ \mathrm{TiO}_{2}$ and $\mathrm{Pt}$ nanowires $/ \mathrm{TiO}_{2}$ catalytic nanodiodes during methanol oxidation reaction. e Selectivity to methyl formate and f chemicurrent yield under methanol oxidation on the Schottky nanodiodes with different oxide support or stack order of nanowires. All results were obtained under methanol 4 Torr and $\mathrm{O}_{2}$ to 760 Torr. 
metal nanocatalyst at interfacial sites when metal nanoparticles were supported by $\mathrm{TiO}_{2}{ }^{44-46}$. In addition, earlier catalytic studies on two-dimensional $\mathrm{Pt}$ nanowire arrays deposited on reducible support (e.g., $\mathrm{CeO}_{2}$ and $\mathrm{ZrO}_{2}$ ) demonstrated increased catalytic activity on $\mathrm{Pt}$ nanowires with nanoscale metal-oxide interfaces than in Pt film or Pt(111) single crystal surface ${ }^{33}$. Therefore, in this study, we conclude that much-improved selectivity in our two-dimensional $\mathrm{TiO}_{2}$ supported $\mathrm{Pt}$ nanowire arrays is associated with the nanoscale interfacial sites formed between Pt nanowires and $\mathrm{TiO}_{2}$.

To more clearly show the selectivity differences and assess these differences on $\mathrm{Pt}$ nanowires/ $/ \mathrm{TiO}_{2}$ and $\mathrm{Pt}$ film $/ \mathrm{TiO}_{2}$, the selectivity according to methanol conversion at $343 \mathrm{~K}$ was plotted, as shown in Fig. 2c. We divided the regions for each section of conversion, calculated the TOF for each $\mathrm{CO}_{2}$ and methyl formate production, then calculated selectivity and compared them in $\mathrm{Pt}$ nanowires/ $/ \mathrm{TiO}_{2}$ and $\mathrm{Pt}$ film/ $/ \mathrm{TiO}_{2}$. The selectivity of each catalyst according to methanol conversion was almost constant, which means that the reaction kinetics of methanol oxidation were constant within this comparable methanol conversion region. In addition, when comparing selectivity obtained from $\mathrm{Pt}$ nanowires $/ \mathrm{TiO}_{2}$ and $\mathrm{Pt}$ film $/ \mathrm{TiO}$, it was found that $\mathrm{Pt}$ nanowires $/ \mathrm{TiO}_{2}$ with $\mathrm{Pt}-\mathrm{TiO}_{2}$ interface showed higher selectivity in all methanol conversion regions. Plots of selectivity vs. conversion measured at $353 \mathrm{~K}$ were also shown in the Supplementary Fig. 9 and higher selectivity was observed for $\mathrm{Pt}$ nanowires $/ \mathrm{TiO}_{2}$ catalyst in all conversion regions at this temperature. Through this comparison of selectivity according to conversion, it can be seen that the metal-oxide interface plays a critical role in enhancing selectivity within the comparable methanol conversion region.

Efficiency comparison of hot electron generation. To elucidate the unique electronic structures of the nanoscale metal-oxide interface, we calculated the efficiency of the hot electrons produced by the chemical reaction using the chemicurrent and reactivity results. As the measured current of reaction-induced hot electron is linearly proportional to the reactivity ${ }^{30,47}$, the chemicurrent generated by the catalytic methanol oxidation on the catalytic nanodiode can be described as Eq. (1)

$$
I=\alpha q A N_{\mathrm{Pt}} \mathrm{TOF}
$$

where $\alpha$ is the chemicurrent yield, $q$ is the elementary charge, $A$ is the active area of the Pt catalyst, $N_{\mathrm{Pt}}$ is the number of Pt sites per $\mathrm{mm}^{2}$, and TOF is the rate of methanol oxidation ${ }^{10}$. Therefore, we can obtain the chemicurrent yield, which is the probability of non-adiabatic electronic excitation forming one molecule of the product during a chemical reaction (i.e., the number of hot electrons captured per unit chemical reaction on the nanodiode surface). As shown in Fig. $2 \mathrm{~d}$, the chemicurrent yield, the efficiency of hot electron generation on the catalyst surface was compared for two cases. There was a reasonable chemicurrent density in $\mathrm{Pt}$ film $/ \mathrm{TiO}_{2}$ nanodiode, but it can be said that the reaction occurred completely on the Pt surface in the Pt film because the interfacial sites were not exposed to the methanol oxidation environment. In the Pt film/ $/ \mathrm{TiO}_{2}$, the thickness of the Pt film was $5 \mathrm{~nm}$, making the effect of the substrate negligible (see Supplementary Note 3 for details). Selectivity was low in Pt film without $\mathrm{Pt}-\mathrm{TiO}_{2}$ interface (Fig. 2b, c), which resulted in a smaller hot electron excitation than in $\mathrm{Pt}$ nanowires $/ \mathrm{TiO}_{2}$ nanodiode. In addition, all the experimental results (e.g., TOF, chemicurrent density, and chemicurrent yield) were calibrated to the surface area of Pt. The number of Pt sites for nanowire arrays was calculated by geometrical assumptions (e.g., the Pt nanowire was considered to be rectangular and standing upright on a planar oxide support); therefore, the surface area effect of nanowires can be excluded. As demonstrated by the previous results in the $\mathrm{Pt}$ film $/ \mathrm{TiO}_{2}$ nanodiode, there is a significant influence of selectivity to chemicurrent yield (i.e., as selectivity to methyl formate increased, the generation of hot electrons was enhanced); due to this fact, the chemicurrent yield of Pt nanowires/ $\mathrm{TiO}_{2}$ was higher than Pt film/ $/ \mathrm{TiO}_{2}$, owing to the higher selectivity of Pt nanowires/ $\mathrm{TiO}_{2}$ that have an exposed $\mathrm{Pt}-\mathrm{TiO}_{2}$ interface. We note that in our previous research, we found that hot electrons are generated much more in the reaction to methyl formate than $\mathrm{CO}_{2}{ }^{30}$ and it can be concluded that enhanced hot electron excitation obtained on $\mathrm{Pt}$ nanowires $/ \mathrm{TiO}_{2}$ indeed originates from their improved selectivity on nanoscale $\mathrm{Pt}-\mathrm{TiO}_{2}$ interfacial sites. Recently, we fabricated a Schottky nanodiode that formed a $\mathrm{Pt} / \mathrm{CoO}$ interface and reported a significant increase in catalytic activity and hot electron excitation by hydrogen oxidation ${ }^{48,49}$. Thus, the improved partial oxidation selectivity when $\mathrm{Pt}$ nanowires were supported on $\mathrm{TiO}_{2}$ can be attributed to the $\mathrm{Pt}-\mathrm{TiO}_{2}$ interfacial sites formed in the nanodiode, and owing to this increased selectivity, the efficiency of hot electron excitation was enhanced. Hence, the most striking finding of these results was that the Pt$\mathrm{TiO}_{2}$ interface could promote the partial oxidation reaction to form methyl formate and thereby enhance the hot electron generation on the catalyst. Furthermore, from the observation of change in the chemicurrent yield according to the partial pressure of methanol (i.e., according to product formation), we can also demonstrate that the efficiency of hot electron excitation was greatly affected by selectivity to methyl formate, not total activity (see Supplementary Note 4 and Supplementary Figs. 10 and 11 for details). In addition, for reliable comparison between the interface effects in multi-path reactions and those in one-path reactions, we carried out comparative experiments and examined the results of TOF and chemicurrent for the $\mathrm{Pt}$ nanowires $/ \mathrm{TiO}_{2}$ and the $\mathrm{Pt}$ film $/ \mathrm{TiO}_{2}$ in a hydrogen oxidation reaction whose product is only water. In the hydrogen oxidation reaction (i.e., hydrogen 4 Torr and oxygen to 760 Torr), the change in activity and the efficiency of hot electron excitation by the $\mathrm{Pt}-\mathrm{TiO}_{2}$ interface did not appear (Supplementary Note 5 and Supplementary Figs. 12 and 13), which indicates that selectivity is the key factor in influencing chemicurrent yield.

Control experiments changing stack order and oxide support. To further demonstrate the effect of the $\mathrm{Pt}_{-} \mathrm{TiO}_{2}$ interface, we conducted further control experiments that changed the stack order or composition of supported nanowires. This involved fabricating $\mathrm{TiO}_{2}$ nanowires/Pt inverse structure with $\mathrm{TiO}_{2}$ nanowires deposited on $\mathrm{Pt}$ thin film and $\mathrm{Pt}$ nanowires $/ \mathrm{SiO}_{2}$ structure, and obtaining the selectivity and chemicurrent yield, as shown in Fig. 2e, f. We obtained and compared all the reaction data (e.g., TOF and selectivity) at each nanodiode by measuring the reaction rate at low methanol conversion (i.e., $<10 \%$ ) under a kinetically controlled regime (Supplementary Fig. 14). As shown in Supplementary Fig. 15a, we fabricated the inverse structure of $\mathrm{TiO}_{2}$ nanowire arrays on the $\mathrm{Pt}$ film/ $/ \mathrm{TiO}$ diode with exactly the same size and period of nanowires with width of $20 \mathrm{~nm}$ (i.e., $\mathrm{TiO}_{2}$ nanowires (width $20 \mathrm{~nm}$ )/Pt film $/ \mathrm{TiO}_{2}$ inverse catalytic nanodiode) to form the inverse $\mathrm{TiO}_{2}$ - Pt interface. The device was constructed, as shown in Supplementary Fig. 15b, and the Schottky barrier height was $0.88 \mathrm{eV}$, which was similar to the $\mathrm{Pt}$ film $/ \mathrm{TiO}_{2}$ and $\mathrm{Pt}$ nanowires/ $/ \mathrm{TiO}_{2}$. Under methanol 4 Torr and oxygen to 760 Torr, the steady-state chemicurrent was measured, and the stability of the device under reaction condition was confirmed by checking the unchanged electrical properties (Supplementary Fig. 15c, d). As the width of the $\mathrm{TiO}_{2}$ nanowire arrays on Pt film was the same as the previous Pt nanowire arrays on the $\mathrm{TiO}_{2}$ structure, the ratio of interface to metal site was also 
the same for both structures (i.e., Pt nanowires (width $20 \mathrm{~nm}$ )/ $\mathrm{TiO}_{2}$ and $\mathrm{TiO}_{2}$ nanowires (width $20 \mathrm{~nm}$ ) $/ \mathrm{Pt}$ film/ $/ \mathrm{TiO}_{2}$ ). For this reason, the selectivity of the inverse structure was similar to those of the previous structure in which the $\mathrm{Pt}$ nanowires were on the $\mathrm{TiO}_{2}$ with the same width, as shown in Fig. 2e. As the selectivity in $\mathrm{Pt}$ nanowires/TiO 2 and $\mathrm{TiO}_{2}$ nanowires/Pt was almost the same, the chemicurrent yields in both systems were also similar (Fig. 2f). Therefore, whether the Pt nanowires were on $\mathrm{TiO}_{2}$ or the $\mathrm{TiO}_{2}$ nanowires were on the $\mathrm{Pt}$ film, the same amount of interface ratio could not affect the selectivity or hot electron generation; if the same ratio of metal-oxide interfacial sites formed, it can be seen that the stack order had little effect on the chemical reaction and hot electron excitation was hardly affected. This control experiment in depositing $\mathrm{TiO}_{2}$ nanowires on the $\mathrm{Pt}$ film indicates that the nanoscale $\mathrm{Pt}-\mathrm{TiO}_{2}$ interface plays an important role in determining selectivity and hot electron generation in methanol oxidation.

Instead of the $\mathrm{Pt}-\mathrm{TiO}_{2}$ interface, the catalytic reaction experiment was carried out after depositing the Pt nanowire arrays on a non-reducible $\mathrm{SiO}_{2}$ support known to have little metal-support interface effect ${ }^{50,51}$. In the structure where the $\mathrm{Pt}$ nanowires were placed on the $\mathrm{SiO}_{2}$ support, the selectivity to produce methyl formate was not high, coming close to that of the $\mathrm{Pt}$ film $/ \mathrm{TiO}_{2}$ (Fig. 2e). Hence, the shape and size effect of the $\mathrm{Pt}$ nanowires could be excluded from the results of similar selectivity for $\mathrm{Pt}$ nanowires $/ \mathrm{SiO}_{2}$ and $\mathrm{Pt}$ film. Unlike on other oxide supports, previously reported results also showed similar activity to Pt nanowire arrays on $\mathrm{SiO}_{2}$ supports and to both $\mathrm{Pt}$ film and single $\mathrm{Pt}(111)$ crystals $^{33}$. Through this control experiment in which Pt nanowires were deposited on $\mathrm{SiO}_{2}$, which is a nonreducible support, it was found that the $\mathrm{Pt}-\mathrm{TiO}_{2}$ interface has a greater effect on selectivity improvement than the $\mathrm{Pt}-\mathrm{SiO}_{2}$ interface. Pt nanowires may have exhibited different selectivity when deposited on $\mathrm{SiO}_{2}$ and $\mathrm{TiO}_{2}$ supports due to the difference in Lewis acidity between the two oxide supports ${ }^{52}$.

To demonstrate the Lewis acid/base properties of these two oxide supports in a methanol oxidation reaction environment, we investigated the charge transfer from the adsorbate to the support surface when reactant methanol molecule was adsorbed on $\mathrm{TiO}_{2}$ and $\mathrm{SiO}_{2}$ support by using DFT calculation (see Supplementary Note 6 and Supplementary Figs. 16 and 17 for calculation details). As shown in Supplementary Fig. 17, when the methanol was adsorbed on two oxide surfaces, the electron density on the methanol basis was calculated (with a negative sign indicating a loss of electrons), yielding -0.07 when adsorbed on the $\mathrm{TiO}_{2}$ surface and +0.01 when adsorbed on the $\mathrm{SiO}_{2}$ surface. This result implies that when the adsorption of methanol occurs on the two oxide surfaces, electron transfer from methanol to surface occurs on the $\mathrm{TiO}_{2}$ surface (i.e., Lewis acid) and electron transfer from surface to methanol occurs a little on the $\mathrm{SiO}_{2}$ surface (i.e., Lewis base). Therefore, through this Bader charge analysis, it was found that the Lewis acidity of $\mathrm{TiO}_{2}$ is stronger than that of the surface of $\mathrm{SiO}_{2}$ when methanol oxidation reaction occurs. Therefore, when $\mathrm{Pt}$ nanowires were deposited on the $\mathrm{TiO}_{2}$ support, which has a higher Lewis acidity than $\mathrm{SiO}_{2}$, it showed higher partial oxidation selectivity. A previous study also indicated that the selectivity of methyl formate production in the methanol oxidation reaction increased as the Lewis acidity of the oxide support increased when the metal catalyst was introduced to the oxide support ${ }^{53}$. As a result, it has been confirmed that the Pt$\mathrm{SiO}_{2}$ interface had little metal-support interface effect compared to the $\mathrm{Pt}-\mathrm{TiO}_{2}$ interface, due to the different acid/base properties of $\mathrm{SiO}_{2}$ and $\mathrm{TiO}_{2}$. Hence, the increase in selectivity only when $\mathrm{Pt}$ nanowires were deposited on $\mathrm{TiO}_{2}$, which was reducible support (i.e., strong Lewis acidity), rather than non-reducible $\mathrm{SiO}_{2}$, lends strong evidence to the claim that catalytic reactions occur mainly at nanoscale $\mathrm{Pt}-\mathrm{TiO}_{2}$ interface sites.

Change of selectivity and efficiency of hot electron. Because of a lack of definitive experimental evidence, the fundamental role and effect of metal-oxide interfacial sites are still debated. To prove this hypothesis, it is necessary to observe the change in selectivity according to the ratio of the $\mathrm{Pt}-\mathrm{TiO}_{2}$ interfacial sites. The change in selectivity as a function of the density of the metal-oxide interface provides evidence that the reaction primarily occurs at interfacial sites of metal-support when reducible oxides are used as supports for metal nanocatalysts ${ }^{15,54}$. Recently, we found a shift in catalytic activity when controlling the concentration of the metal-oxide interface under $\mathrm{H}_{2}$ oxidation and $\mathrm{CO}$ oxidation, indicating that higher catalytic activity was observed when more metal-oxide interfaces were created $^{55,56}$. Moreover, a previous study also reported that higher butanol production selectivity was achieved by generating more metal-oxide interfaces, as the density of Pt nanoparticles on oxide support increases by changing the Langmuir-Blodgett surface pressure ${ }^{57}$. In addition, when Pt, $\mathrm{Pd}$, and $\mathrm{Ni}$ nanocatalysts were supported by oxide, there was a previous study in which the $\mathrm{CO}$ oxidation reactivity increased as the size of the nanocatalysts decreased, since the ratio of interfacial sites (i.e., perimeter and corner atoms) increased as the particle size decreased ${ }^{17}$. Therefore, to further investigate the effect of the metal-oxide interface ratio, we fabricated a nanodiode based on $\mathrm{Pt}$ nanowire arrays with width of $15 \mathrm{~nm}$; the ratio of interface to metal sites of these nanowire arrays was higher than the earlier Pt nanowire arrays with width of $20 \mathrm{~nm}$. In other words, a higher ratio of $\mathrm{Pt}-\mathrm{TiO}_{2}$ interface to metal sites could be modeled by decreasing the width of Pt nanowires. Concurrently, we fabricated the Pt nanowire arrays by increasing the width to $50 \mathrm{~nm}$ and depositing it on the $\mathrm{TiO}_{2}$ support to produce a catalytic nanodevice. To further observe the selectivity and hot electron excitation changes according to the width control of $\mathrm{Pt}$ nanowires, both the selectivity and chemicurrent yield were measured as the width of the nanowires was changed (see Supplementary Note 7 and Supplementary Figs. 18 and 21 for details).

Figure $3 \mathrm{a}-\mathrm{c}$ represent the SEM image of the fabricated nanowire arrays of $\mathrm{Pt}$ nanowires (width $15 \mathrm{~nm}$ ) $/ \mathrm{TiO}_{2}, \mathrm{Pt}$ nanowires (width $20 \mathrm{~nm}$ ) $/ \mathrm{TiO}_{2}$, and $\mathrm{Pt}$ nanowires (width $50 \mathrm{~nm}$ ) $/ \mathrm{TiO}_{2}$, respectively. The selectivity and quantity of hot electron generation from methanol 4 Torr and oxygen to 760 Torr in each nanodiode were compared according to the width of Pt nanowires by adding the results from the fabricated devices (Fig. 3d, e). All the current density measured under methanol oxidation and non-reactive conditions is shown in Supplementary Fig. 22. As shown in Fig. 3d, compared to $\mathrm{Pt}$ film, selectivity increased when $\mathrm{Pt}$ nanowires were deposited on $\mathrm{TiO}_{2}$ support and it was confirmed that selectivity was enhanced as the width of the Pt nanowires decreased. As the width of $\mathrm{Pt}$ nanowires on $\mathrm{TiO}_{2}$ was reduced from $50 \mathrm{~nm}$ to $15 \mathrm{~nm}$, the ratio of $\mathrm{Pt}-\mathrm{TiO}_{2}$ interface to metal increased, which enhanced selectivity to methyl formate formation, owing to the increased ratio of interfacial sites. In addition, when comparing selectivity according to methanol conversion, the selectivity trend according to the width of nanowires was clearly shown in all methanol conversion regions (Supplementary Fig. 23).

As shown in Fig. 3e, when comparing the chemicurrent yield detected in catalytic nanodevices as a function of the width of $\mathrm{Pt}$ nanowires, it can be seen that the chemicurrent yield increased (i.e., higher efficiency for reaction-induced hot electron excitation) as the width of nanowires decreased, owing to the enhanced 

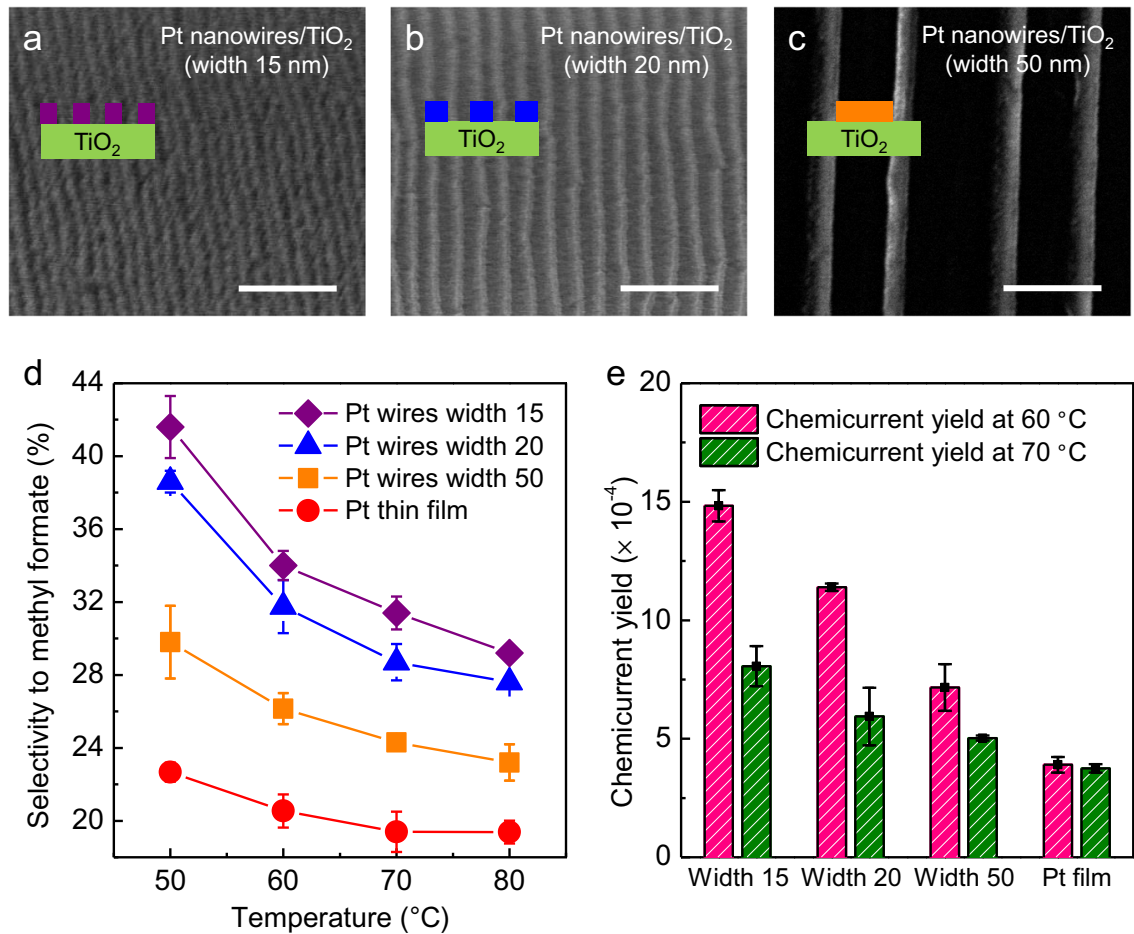

Fig. 3 Selectivity and chemicurrent yield on nanowire arrays with different widths. SEM images of a Pt nanowires/ $\mathrm{TiO}_{2}$ with a width of $15 \mathrm{~nm}$, b Pt nanowires $/ \mathrm{TiO}_{2}$ with a width of $20 \mathrm{~nm}$, and $\mathbf{c}$ Pt nanowires $/ \mathrm{TiO}_{2}$ with a width of $50 \mathrm{~nm}$. Scale bars are $200 \mathrm{~nm}$. $\mathbf{d}$ Selectivity to methyl formate under methanol oxidation on the Schottky nanodiodes at different temperatures with different widths. e Chemicurrent yield for methanol oxidation on the catalytic nanodiodes of width 15 ( $\mathrm{Pt}$ nanowires $/ \mathrm{TiO}_{2}$ with a width of $15 \mathrm{~nm}$ ), width 20 (Pt nanowires $/ \mathrm{TiO}_{2}$ with a width of $20 \mathrm{~nm}$ ), width 50 (Pt nanowires/ $\mathrm{TiO}_{2}$ with a width of $50 \mathrm{~nm}$ ), and Pt film ( $\mathrm{Pt} \mathrm{film} / \mathrm{TiO}_{2}$ ) measured both at 333 and $343 \mathrm{~K}$. All results were obtained under methanol $4 \mathrm{Torr}$ and $\mathrm{O}_{2}$ to 760 Torr.

selectivity by the increased ratio of interfacial sites. Therefore, we can conclude that as the width of the Pt nanowires decreased, higher selectivity to methyl formate was observed due to the increased ratio of $\mathrm{Pt}-\mathrm{TiO}_{2}$ interface, thereby enhancing hot electron excitation in catalytic nanodiodes. In all nanodiodes, the Schottky barrier height was obtained by fitting each $I-V$ curve to thermionic emission theory, as shown in Supplementary Table 3. As mentioned earlier, this Schottky barrier acts as a filter for hot electron transfer, and only energetic electrons whose excess chemical energy by energy conversion is higher than the Schottky barrier height can be detected on this metal-semiconductor nanodiode. Here, despite the higher Schottky barrier height in the $\mathrm{Pt}$ nanowires/ $\mathrm{TiO}_{2}$ nanodiode with width of $15 \mathrm{~nm}$ (i.e., $\sim 1.02$ and $0.85 \mathrm{eV}$ for $\mathrm{Pt}$ nanowires (width $15 \mathrm{~nm}$ ) $/ \mathrm{TiO}_{2}$ and $\mathrm{Pt}$ nanowires (width $20 \mathrm{~nm}$ ) $/ \mathrm{TiO}_{2}$, respectively), the higher hot electron detection indicates that the enhanced selectivity owing to the increased $\mathrm{Pt}-\mathrm{TiO}_{2}$ interface concentration has a significant effect on hot electron excitation, neglecting the decrease in hot electron transfer due to the increased barrier. Therefore, as the structure exhibiting smaller width has a higher ratio of metaloxide interface to metal sites, it exhibits higher partial oxidation selectivity to form methyl formate, thereby increasing reactioninduced hot electron excitation in methanol oxidation. The width dependence of selectivity of these $\mathrm{TiO}_{2}$ supported nanowires indicates that the selective partial oxidation reaction primarily occurs at the metal-oxide interface. Thus, the well-controlled width of oxide supported nanowires through our lithography technique can easily tune the ratio of metal-oxide interface, which changed the catalytic reaction significantly.

DFT calculations for two possible pathways. To gain further insight into the enhanced selectivity of methyl formate on
Pt- $\mathrm{TiO}_{2}$ interface compared to Pt film, we performed DFT calculations on the Pt nanorod model on $\mathrm{TiO}_{2}(110)$. Two possible reaction pathways toward $\mathrm{CO}_{2}$ and methyl formate formation are laid out in Supplementary Fig. 24, and detailed mechanisms, including all elementary steps and associated energetics are presented in Supplementary Table 4, following previously suggested mechanisms $s^{30,58}$. First, as shown in Supplementary Fig. 24, methanol is oxidized to formaldehyde, which can further oxidize to form $\mathrm{CO}_{2}$ or undergo $\mathrm{C}-\mathrm{C}$ coupling to form methyl formate. As the reaction of the formaldehyde intermediate determines which product is produced between methyl formate and $\mathrm{CO}_{2}{ }^{26}$, we considered the reaction channel from formaldehyde in two catalysts to compare the selectivity in the methanol oxidation reaction. The free energetics from formaldehyde to both products are presented in Fig. 4a, b. To initiate the reaction, methanol preferred to adsorb on the Ti top site of $\mathrm{TiO}_{2}$, whereas oxygen preferred the $\mathrm{Pt}$ sites in the present $\mathrm{Pt}-\mathrm{TiO}_{2}$ interfacial structure. Thus, the reaction would mainly take place by transferring the protons from adsorbates on the Ti sites to oxygen (or $\mathrm{OH})$ on $\mathrm{Pt}$. However, once ${ }^{*} \mathrm{CH}_{2} \mathrm{O}$ loses its proton to ${ }^{*} \mathrm{OH}\left({ }^{*} \mathrm{CH}_{2} \mathrm{O}+\right.$ $\left.{ }^{*} \mathrm{OH} \rightarrow{ }^{*} \mathrm{HCO}+{ }^{*} \mathrm{H}_{2} \mathrm{O}\right),{ }^{*} \mathrm{HCO}$ prefers and moves to the $\mathrm{Pt}$ sites. Consequently, the final reaction $\mathrm{CO}+\mathrm{O} \rightarrow \mathrm{CO}_{2}$ occurs above the Pt sites.

As the selectivity is determined by the activation barrier in the reaction determining steps (RDSs), we calculated the reaction energy barriers for $\mathrm{CO}_{2}$ and methyl formate on the Pt nanorods on $\mathrm{TiO}_{2}(110)$ modeling Pt nanowires supported on $\mathrm{TiO}_{2}$. The Pt$\mathrm{TiO}_{2}$ energetics were then compared to our previous calculation on a three-atomic-layer of $\mathrm{Pt}(111)$ surface, representing the reaction on the Pt film surface (Supplementary Table 5) ${ }^{30}$. As shown in Fig. 4a, on $\mathrm{Pt}_{-} \mathrm{TiO}_{2}(110)$, the largest barrier step for the methyl formate formation was the last dehydration step 

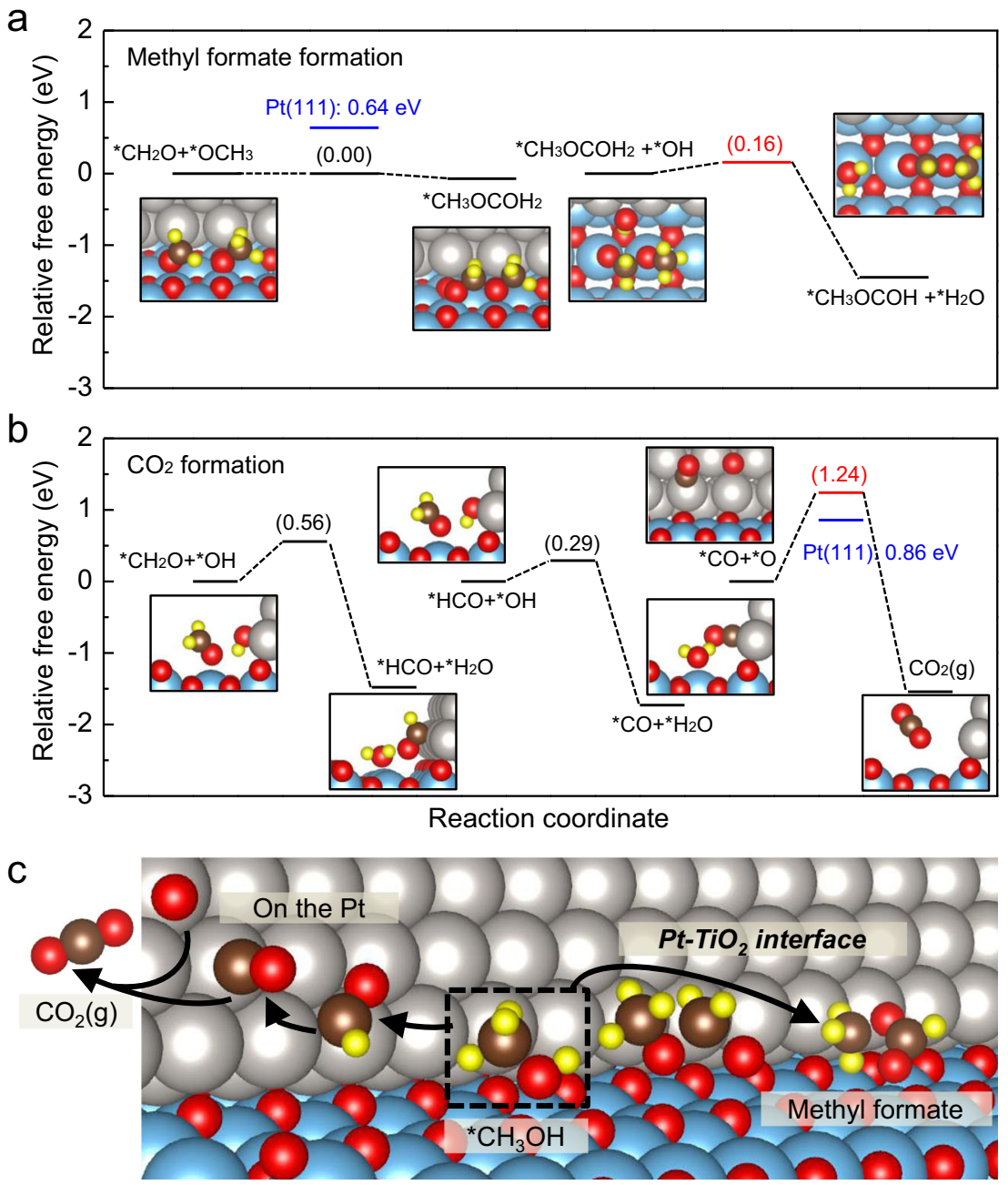

Fig. 4 Calculated activation barrier for $\mathbf{P t}$ nanorod on $\mathbf{T i O}_{\mathbf{2}}(\mathbf{1 1 0})$ compared with $\mathbf{P t ( 1 1 1 ) . ~ O p t i m i z e d ~ f r e e - e n e r g y ~ p r o f i l e s ~ f o r ~} \mathbf{a}$ methyl formate and $\mathbf{b}$ the $\mathrm{CO}_{2}$ formation path with reaction barriers $(\Delta \mathrm{G})$. Barriers with red and blue indicate the RDS of each path for $\mathrm{Pt}$ nanorod structure on $\mathrm{TiO}{ }_{2}(110)$ and $\mathrm{Pt}$ (111), respectively. c Schematic drawing showing formation of $\mathrm{CO}_{2}$ and methyl formate in methanol oxidation on $\mathrm{Pt}$ nanorod/TiO $\mathrm{O}_{2}(110)$. Species marked with an asterisk $\left(^{\star}\right)$ are adsorbed on the surface. The gray, blue, brown, red, and yellow balls indicate Pt, Ti, C, O, and $\mathrm{H}$, respectively.

$\left({ }^{*} \mathrm{CH}_{3} \mathrm{OCOH}_{2}+{ }^{*} \mathrm{OH} \rightarrow{ }^{*} \mathrm{CH}_{3} \mathrm{OCOH}+{ }^{*} \mathrm{H}_{2} \mathrm{O}\right)$ with a low barrier of $0.16 \mathrm{eV}$. In the case of $\mathrm{Pt}(111)$, the RDS (i.e., the $\mathrm{C}-\mathrm{C}$ coupling step) was different, with a much higher barrier of $0.64 \mathrm{eV}$. The altered RDS was attributed to the different adsorption configuration of $\mathrm{CH}_{2} \mathrm{O}$ that is needed for $\mathrm{C}-\mathrm{C}$ coupling and has changed in the respective sites, as shown in Supplementary Fig. 25. In other words, on Pt(111), C and O are simultaneously adsorbed on the surface, requiring the rupture of the metal- $\mathrm{C}$ bonding for $\mathrm{C}-\mathrm{C}$ coupling, whereas on $\mathrm{Pt}-\mathrm{TiO}_{2}(110)$ only $\mathrm{O}$ is bonded to the surface with an easy rotation of the methyl group for the coupling reaction.

The RDS in the $\mathrm{CO}_{2}$ formation path on both $\mathrm{Pt}_{-} \mathrm{TiO}_{2}(110)$ and $\mathrm{Pt}(111)$ is the last $\mathrm{C}-\mathrm{O}$ coupling step $\left(\mathrm{CO}+\mathrm{O} \rightarrow \mathrm{CO}_{2}\right)$, but the activation barrier was much larger on $\mathrm{Pt}-\mathrm{TiO}_{2}(110)(1.24 \mathrm{eV})$ than on $\mathrm{Pt}(111)(0.86 \mathrm{eV})$. This intriguing result could be attributed to a change in the reaction mechanism; on $\mathrm{Pt}(111)$, the reaction occurs via the Langmuir-Hinshelwood mechanism $\left({ }^{*} \mathrm{CO}+{ }^{*} \mathrm{O} \rightarrow \mathrm{CO}_{2(\mathrm{~g})}\right)$, whereas on the interfacial Pt sites of the Pt- $\mathrm{TiO}_{2}(110)$, the reaction follows the Eley-Rideal mechanism $\left(\mathrm{CO}_{(\mathrm{g})}+{ }^{*} \mathrm{O} \rightarrow \mathrm{CO}_{2(\mathrm{~g})}\right)$ where $\mathrm{CO}$ desorbs first and then forms a new bond with adsorbed $\mathrm{O}$. The binding energy of $\mathrm{CO}_{2}$ on the $\mathrm{TiO}_{2}$ surface was calculated, because the lower production of $\mathrm{CO}_{2}$ may be due to the adsorption of $\mathrm{CO}_{2}$ on $\mathrm{TiO}_{2}$. As shown in Supplementary Fig. 26, the binding energy of $\mathrm{CO}_{2}$ on the $\mathrm{TiO}_{2}$ surface was $-0.21 \mathrm{eV}$, which is an energy level that can be sufficiently desorbed even at room temperature ${ }^{59}$; thus, the reason for the adsorption of $\mathrm{CO}_{2}$ on the $\mathrm{TiO}_{2}$ cannot be the low production of $\mathrm{CO}_{2}$. In addition, in the theoretical calculation on the $\mathrm{Pt}$ nanorod $/ \mathrm{TiO}_{2}(110)$ model, $\mathrm{HCO}$, which is the intermediate before $\mathrm{CO}_{2}$ is generated, prefers adsorption to the Pt surface and $\mathrm{CO}_{2}$ generation occurs at the Pt site; thus, $\mathrm{CO}_{2}$ adsorption in $\mathrm{TiO}_{2}$ can also be excluded. Furthermore, as mentioned above, since the reaction mechanism in which $\mathrm{CO}_{2}$ was generated by methanol oxidation was revealed by DFT calculation as an Eley-Rideal mechanism $\left(\mathrm{CO}_{(\mathrm{g})}+{ }^{*} \mathrm{O} \rightarrow \mathrm{CO}_{2(\mathrm{~g})}\right)$ in the $\mathrm{Pt}$ nanorod/TiO $2(110)$ model, there was no state in which $\mathrm{CO}_{2}$ was adsorbed during the methanol oxidation reaction. Thus, the experimentally observed enhanced selectivity toward methyl formate over $\mathrm{CO}_{2}$ on the $\mathrm{Pt}$ nanorod on $\mathrm{TiO}_{2}(110)$ compared to thin $\mathrm{Pt}$ film can be understood by the much lower activation barrier to form methyl formate (0.64 for $\mathrm{Pt}(111) \rightarrow 0.16 \mathrm{eV}$ for $\left.\mathrm{Pt}-\mathrm{TiO}_{2}(110)\right)$, as well as the increased activation barrier to form $\mathrm{CO}_{2}(0.86$ for $\mathrm{Pt}(111) \rightarrow 1.24 \mathrm{eV}$ for Pt$\left.\mathrm{TiO}_{2}(110)\right)$. The pathways in which $\mathrm{CO}_{2}$ and methyl formate were generated in $\mathrm{Pt}$ nanorod/ $/ \mathrm{TiO}_{2}(110)$ investigated by theoretical simulation are shown in Fig. $4 \mathrm{c}$. Here, $\mathrm{CO}_{2}$ was generated on the $\mathrm{Pt}$ surface and methyl formate formed by reacting the intermediate present on $\mathrm{TiO}_{2}$ with $\mathrm{OH}$ present on $\mathrm{Pt}$, and the importance of the $\mathrm{Pt}-\mathrm{TiO}_{2}$ interface to improve the selectivity of methyl formate production could be theoretically proven. Hence, we can prove the 
experimental results of the reduced $\mathrm{CO}_{2}$ production and increased methyl formate production in $\mathrm{Pt}$ nanowires $/ \mathrm{TiO}_{2}$ compared to $\mathrm{Pt}$ film/ $/ \mathrm{TiO}_{2}$ (Fig. 2b, c). We note that a similar effect, changing activation barriers when the interfacial sites formed, was also demonstrated in the previous combined theory and experimental studies for Pt-NiO and Pt-CoO interfaces ${ }^{49,60}$. Therefore, all these results can point to the conclusion of selectivity enhancement on metal-oxide interfacial sites in $\mathrm{Pt}$ nanowires $/ \mathrm{TiO}_{2}$, as these theoretical calculation results demonstrate the increased barrier for $\mathrm{CO}_{2}$ generation and the decreased barrier for methyl formate production. As hot electrons generated by non-adiabatic electronic excitation by exothermic catalytic reaction are excited states, it is challenging to directly calculate the transfer of excited hot electrons through DFT calculation and compare them in these two systems. However, we note that our earlier DFT calculations ${ }^{30}$ show the relationship between the generation of methyl formate and hot electron generation. In this study, it was found that the selectivity of methyl formate formation was enhanced when the $\mathrm{Pt} / \mathrm{TiO}_{2}$ interface was formed, which was due to the difference in the activation barrier confirmed by theoretical calculations. Our quantitative comparison between the selectivity of methyl formate and $\mathrm{CO}_{2}$ on $\mathrm{Pt}-\mathrm{TiO}_{2}$ and that of $\mathrm{Pt}(111)$ via DFT calculations, the enhanced hot electron generation on $\mathrm{Pt}-\mathrm{TiO}_{2}$ interface can be rationalized. These are important findings, because these works are the first visualization of the unique electronic property of the metaloxide perimeter in oxide supported-metal nanowires obtained by real-time measurement of excited hot electrons from the exothermic surface chemical reaction.

\section{Discussion}

In this study, we have investigated the metal-oxide interface effect on partial oxidation selectivity using a newly designed Schottky nanodiode composed of two-dimensional Pt nanowire arrays deposited on $\mathrm{TiO}_{2}$, and the changed selectivity influenced the magnitude of reaction-induced hot electron flow excited by methanol oxidation. Compared to $\mathrm{Pt}$ films on $\mathrm{TiO}_{2}$ where the interface was not exposed to the reaction environment, the Pt$\mathrm{TiO}_{2}$ interface was exposed to the gaseous environment when the $\mathrm{Pt}$ nanowire arrays were placed on $\mathrm{TiO}_{2}$. The effect of the metaloxide interface can be identified by comparing the selectivity in these two structures. We observed that the formation of the nanoscale $\mathrm{Pt}-\mathrm{TiO}_{2}$ interface showed that selectivity to methyl formate formation was much larger in Pt nanowire arrays than in Pt films. As the efficiency of hot electron excitation by exothermic catalytic reaction was attributed to selectivity, the chemicurrent yield showed much higher in Pt nanowire arrays than on Pt film owing to enhanced selectivity, confirming the role of metal-oxide interfacial sites in enhancing selectivity and reaction-induced electron transfer. Calculation of the activation barrier by DFT calculation in two models of $\mathrm{Pt}$ nanorod/TiO ${ }_{2}(110)$ and $\mathrm{Pt}(111)$ revealed barrier differences due to different molecular adsorption orientations and reaction mechanisms in the two models, which indicates improved selectivity at the $\mathrm{Pt}-\mathrm{TiO}_{2}$ interface. This study is the first to directly observe the reaction-induced electronic excitation at the nanoscale metal-oxide interface, which was made possible by the real-time detection of hot electrons excited by catalytic reaction in the newly designed $\mathrm{Pt}$ nanowires/TiO $\mathrm{O}_{2}$ system. Thus, this technique for using the catalytic nanodiodes provides a powerful and highly sensitive tool for studying the processes of charge transfer at the metal-oxide interface excited by surface chemical reaction. These studies demonstrate that the presence of nanoscale metal-oxide interfaces alters selectivity, thereby influencing reaction-induced electron transfer in heterogeneous catalysts. Tuning the materials and architectures of nanowires catalysts gives rise to the important control mechanism of chemical reaction and hot electron generation.

\section{Methods}

Fabrication of master molds for nanowire transfer printing. Cylinder forming polystyrene-block-poly(dimethylsiloxane) (PS- $b$-PDMS) block copolymers with molecular weights (MWs) of $36 \mathrm{~kg} / \mathrm{mol}$ (SD36) and $48 \mathrm{~kg} / \mathrm{mol}$ (SD48), which form 15 - and $20 \mathrm{~nm}$-wide lines, and hydroxyl-terminated PDMS brush polymer with a MW of $5 \mathrm{~kg} / \mathrm{mol}$ were purchased from Polymer Source, Inc. (Canada). Surfacepatterned Si substrates with a width of $1 \mu \mathrm{m}$ and a period of $1.2 \mu \mathrm{m}$ were fabricated using $\mathrm{KrF}$ photolithography followed by reactive ion etching and used as guiding substrates for the self-assembly of block copolymers. The hydroxyl-terminated PDMS solution dissolved in heptane solvent with a $2 \mathrm{wt} \%$ was spin-coated on the pre-patterned Si substrate. After spin casting, the sample was thermal annealed at $150^{\circ} \mathrm{C}$ and then washed with heptane, to remove unattached polymer residues. SD36 and SD48 block copolymers were dissolved in a mixed solvent of toluene, heptane, and PGMEA ( $1: 1: 1$ by volume) with a $0.6-0.8 \mathrm{wt} \%$ polymer solution. The SD36 and SD48 polymer solutions were spin-cast on the prepared substrates, respectively, and solvent-annealed with toluene vapor for $6-10 \mathrm{~h}$ in the chamber at room temperature to form well-ordered line/space patterns. After the annealing process, the samples were etched by $\mathrm{CF}_{4}$ plasma followed by $\mathrm{O}_{2}$ plasma treatment to obtain oxidized line/space PDMS nanostructures. To form Pt nanowires with 50 $\mathrm{nm}$ width and $200 \mathrm{~nm}$ pitch, the master mold was fabricated using KrF photolithography followed by reactive ion etching process.

Fabrication of n-type $\mathrm{TiO}_{2}$ support for catalytic nanodiodes. A $200 \mathrm{~nm}$ titanium film was deposited by electron beam evaporation with a titanium target using a patterned aluminum shadow mask $\left(4 \times 6 \mathrm{~mm}^{2}\right)$ on a 4 inch $500 \mathrm{~nm} \mathrm{SiO}_{2}$-covered p-type $\mathrm{Si}(100)$ wafer. After its deposition, the titanium film was thermally oxidized in air at $470{ }^{\circ} \mathrm{C}$ for $2.5 \mathrm{~h}$, forming an $n$-type $\mathrm{TiO}_{2}$ film; the sheet resistance was checked during annealing. The electrode with a $50 \mathrm{~nm}$ Ti and a $150 \mathrm{~nm}$ Au thin film was deposited sequentially through a second shadow mask $\left(5 \times 5 \mathrm{~mm}^{2}\right)$ on both sides by electron beam evaporation. The Ti layer was deposited to form ohmic contact with the $n$-type $\mathrm{TiO}_{2}$ surface and the Au layer created the two Ohmic electrodes for the catalytic nanodiodes. At room temperature, all the metal films were deposited with $10 \mathrm{kV}$ of DC voltage in a high-vacuum chamber with a base pressure of $2 \times 10^{-8}$ Torr, which was evacuated using rotary and turbomolecular pumps. The deposition rate of metal was $0.2 \AA \mathrm{s}^{-1}$ until a thin film of $5 \mathrm{~nm}$ was deposited for adhesion on the surface and the deposition rate was then gradually increased to $1.0 \AA \mathrm{s}^{-1}$ until reaching the final thickness of the metal film.

Solvent-assisted nanotransfer printing of Pt nanowire arrays on $\mathrm{TiO}_{2}$ support Poly(methyl methacrylate) (PMMA; $\mathrm{MW}=100 \mathrm{~kg} / \mathrm{mol}$ ) was purchased from Sigma Aldrich, Inc. and dissolved in a mixed solvent of toluene, acetone, and heptane with four wt\% (4.5:4.5:1 by volume). The surface of the master molds was treated with a hydroxyl-terminated PDMS brush to enable the release of the polymer replica film from the master molds. After surface treatment, a PMMA polymer solution was spin-coated onto the master molds. A polyimide (PI) adhesive film (3M, Inc.) was then attached to the top surface of PMMA and smoothly detached from the master mold with the inverted surface topography. Pt nanowires were fabricated by obliquely angled deposition using an e-beam evaporator. The fabricated Pt nanowires/PMMA/PI adhesive film was exposed to a mixed solvent vapor of acetone and heptane $(1: 1$ by volume $)$ at $55^{\circ} \mathrm{C}$ for $20-30 \mathrm{~s}$ then immediately brought into contact with the $\mathrm{TiO}_{2}$ surface of a nanodiode. After the transfer process, the PMMA replica was removed by dipping it into the toluene solvent baths. In addition, to facilitate the movement of hot electrons generated at the interface between Pt nanowires and $\mathrm{TiO}_{2}$, catalytic-inert $\mathrm{Au}$ nanowires with a width of $200 \mathrm{~nm}$ and a period of $1.2 \mu \mathrm{m}$ were also transferred to the fabricated nanodiodes in a mesh type by sequential printing using the same method.

Measurement of reaction rates and chemicurrent. Catalytic methanol oxidation reactions were performed in an ultrahigh vacuum chamber $(1 \mathrm{~L})$ with a base pressure of $1 \times 10^{-8}$ Torr, which was evacuated using rotary and turbomolecular pumps. After isolating with a gate valve, the catalytic reaction was carried out in a batch reactor system filled with a mixture of 1,2 , or 4 Torr of methanol and $\mathrm{O}_{2}$ to atmospheric pressure $(760$ Torr) at room temperature. To inject the methanol vapor into the reaction chamber, the methanol reactant was purified by three cycles of freeze-pump-thawing. All the reactant gas mixtures were recirculated through the reaction line using a Metal Bellows circulation pump at a rate of $2 \mathrm{~L} / \mathrm{min}$. After $0.5 \mathrm{~h}$ of recirculation to reach equilibrium at room temperature, a gas chromatograph (DS 6200) equipped with a thermal conductivity detector, for detection of $\mathrm{CO}_{2}$ product, and a flame ionization detector, for detection of methanol reactant and methyl formate product, were used to separate the gases for analysis. The reaction rates were reported as TOF in units of product molecules produced per $\mathrm{Pt}$ surface site pert second, and the number of $\mathrm{Pt}$ sites for nanowire arrays was calculated by geometrical assumptions. The Pt nanowire was assumed to be rectangular and standing upright on a planar oxide support similar to previous 
study ${ }^{33}$. The signals of electric current for the chemicurrent generated on the catalytic Schottky nanodiode were obtained using a Keithley Instrumentation 2400 SourceMeter at open circuit. Two gold wires were connected to make contact with the two electrical contact pads on either side ( $\mathrm{Au} / \mathrm{Ti}$ layer). The electric current flowing across the Schottky junction was then measured at reactive conditions (1-4 Torr of methanol and $\mathrm{O}_{2}$ to equal 760 Torr) and at non-reactive conditions (760 Torr of pure $\mathrm{O}_{2}$ )

Characterization of fabricated catalytic nanodiodes. The crystalline phases of the Pt nanowire arrays were revealed using XRD patterns (Rigaku D/MAX-2500) taken at a $2 \theta$ scan range of $20-90^{\circ}$, scan speed of $4^{\circ} \mathrm{min}^{-1}$, and step size of $0.01 \AA$ using $\mathrm{Cu} \mathrm{Ka}$ radiation. The chemical oxidation states of the Pt nanowires (Pt $4 \mathrm{f}$ ) before and after catalytic reaction were identified using XPS (Thermo VG Scientific Sigma Probe spectrometer with an X-ray source of Al K-alpha $(1486.3 \mathrm{eV})$ ) with an energy resolution of $0.5 \mathrm{eV}$ full width at half maximum under ultrahigh vacuum conditions with a base pressure of $10^{-10}$ Torr. Field-emission SEM (Magellan 400) and TEM (FEI Titan G2 Cubed 60-300) were used to observe the morphological structures of the Pt nanowires. $I-V$ characteristics of the Pt nanowires/TiO ${ }_{2}$ catalytic nanodiodes were obtained using a Keithley Instrumentation 2400 SourceMeter under various gas conditions (mixtures of 1-4 Torr of methanol with $\mathrm{O}_{2}$ to equal 760 Torr). By fitting the obtained $I-V$ characteristics to the thermionic emission equation, a series resistance, Schottky barrier height, and ideality factor could be obtained.

Simulation methods. DFT calculations were carried out using the VASP code with the Perdew-Burke-Ernzerhof functional ${ }^{61,62}$. The projector augmented wave method was used to describe the potentials of the atoms ${ }^{63}$. Geometries were optimized until the force on each atom was less than $0.05 \mathrm{eV} / \AA$ with a cutoff energy of $400 \mathrm{eV}$. As shown in Supplementary Fig. 16, to simulate the Pt-TiO $\mathrm{T}_{2}$ structure, a $(4 \times 3)$ unit cell was used for rutile $\mathrm{TiO}_{2}(110)$, which contains two layers of $\mathrm{TiO}_{2}$ and a Pt nanorod three layers high and three atoms wide is bonded on top of the $\mathrm{TiO}_{2}(110)$ surface ${ }^{21}$. The bottom layer of $\mathrm{TiO}_{2}$ was fixed to their bulk position and all of the Pt atoms are allowed to relax in the $Z$-direction. $K$-points were sampled using a $2 \times 1 \times 1$ Monkhorst-Pack grid. To model the Pt film, a three-atomic-layer $(3 \times 3)$ of $\mathrm{Pt}(111)$ surface unit cell with the bottom layer fixed was used. Spacing of more than $15 \AA$ in the $z$-direction was applied. The Gibbs free energies were calculated using $\Delta G=\Delta E_{\mathrm{ads}}+\Delta E_{\mathrm{ZPE}}-T \Delta S(T=300 \mathrm{~K})$, where $\Delta E_{a d s}, \Delta E_{\mathrm{ZPE}}$, and $\Delta S$ represent the changes in adsorption energy, zero-point energy, and entropy, respectively. The DFT $+\mathrm{U}$ corrections were applied to the metal d states to correct the on-site Coulomb interaction, and the $U$-value was set at $4.0 \mathrm{eV}^{64}$. The climbing image nudged elastic band method was employed to calculate the activation barriers $^{65}$. The Bader charge analysis was performed to estimate the amount of charge transfer after methanol adsorption on $\mathrm{Pt}-\mathrm{TiO}_{2}$ and $\mathrm{Pt}_{-} \mathrm{SiO}_{2}{ }^{66}$. Negative sign indicates the loss of electrons.

\section{Data availability}

The data that support the findings of this study are available from the corresponding author upon reasonable request.

Received: 7 March 2020; Accepted: 18 November 2020;

Published online: 04 January 2021

\section{References}

1. Somorjai, G. A., Frei, H. \& Park, J. Y. Advancing the frontiers in nanocatalysis, biointerfaces, and renewable energy conversion by innovations of surface techniques. J. Am. Chem. Soc. 131, 16589-16605 (2009).

2. Wodtke, A. M. Electronically non-adiabatic influences in surface chemistry and dynamics. Chem. Soc. Rev. 45, 3641-3657 (2016)

3. Park, J. Y., Kim, S. M., Lee, H. \& Nedrygailov, I. I. Hot-electron-mediated surface chemistry: toward electronic control of catalytic activity. Acc. Chem. Res. 48, 2475-2483 (2015).

4. Somorjai, G. A. \& Park, J. Y. Molecular factors of catalytic selectivity. Angew. Chem. Int. Ed. 47, 9212-9228 (2008).

5. Nienhaus, $\mathrm{H}$. Electronic excitations by chemical reactions on metal surfaces. Surf. Sci. Rep. 45, 1-78 (2002).

6. Hasselbrink, E. How non-adiabatic are surface dynamical processes? Curr. Opin. Solid State Mater. Sci. 10, 192-204 (2006).

7. Wodtke, A. M., Matsiev, D. \& Auerbach, D. J. Energy transfer and chemical dynamics at solid surfaces: the special role of charge transfer. Prog. Surf. Sci. 83, 167-214 (2008).

8. Park, J. Y., Baker, L. R. \& Somorjai, G. A. Role of hot electrons and metal-oxide interfaces in surface chemistry and catalytic reactions. Chem. Rev. 115, 2781-2817 (2015)
9. Gergen, B., Nienhaus, H., Weinberg, W. H. \& McFarland, E. W. Chemically induced electronic excitations at metal surfaces. Science 294, 2521-2523 (2001).

10. Lee, H., Nedrygailov, I. I., Lee, C., Somorjai, G. A. \& Park, J. Y. Chemicalreaction-induced hot electron flows on platinum colloid nanoparticles under hydrogen oxidation: impact of nanoparticle size. Angew. Chem. Int. Ed. 54, 2340-2344 (2015)

11. Karpov, E. G. \& Nedrygailov, I. Nonadiabatic chemical-to-electrical energy conversion in heterojunction nanostructures. Phys. Rev. B 81, 205443 (2010).

12. Hashemian, M., Palacios, E., Nedrygailov, I., Diesing, D. \& Karpov, E. Thermal properties of the stationary current in mesoporous $\mathrm{Pt} / \mathrm{TiO}_{2}$ structures in an oxyhydrogen atmosphere. ACS Appl. Mater. Interfaces 5, 12375-12379 (2013).

13. Diesing, D. \& Hasselbrink, E. Chemical energy dissipation at surfaces under UHV and high pressure conditions studied using metal-insulator-metal and similar devices. Chem. Soc. Rev. 45, 3747-3755 (2016)

14. Nienhaus, $\mathrm{H}$. et al. Electron-hole pair creation at $\mathrm{Ag}$ and $\mathrm{Cu}$ surfaces by adsorption of atomic hydrogen and deuterium. Phys. Rev. Lett. 82, 446 (1999).

15. Ro, I., Resasco, J. \& Christopher, P. Approaches for understanding and controlling interfacial effects in oxide-supported metal catalysts. ACS Catal. 8, 7368-7387 (2018).

16. Sun, Y. N. et al. The interplay between structure and $\mathrm{CO}$ oxidation catalysis on metal-supported ultrathin oxide films. Angew. Chem. Int. Ed. 49, 4418-4421 (2010).

17. Cargnello, M. et al. Control of metal nanocrystal size reveals metal-support interface role for ceria catalysts. Science 341, 771-773 (2013).

18. Tauster, S., Fung, S. \& Garten, R. L. Strong metal-support interactions. Group 8 noble metals supported on titanium dioxide. J. Am. Chem. Soc. 100, 170-175 (1978).

19. Tauster, S., Fung, S., Baker, R. \& Horsley, J. Strong interactions in supportedmetal catalysts. Science 211, 1121-1125 (1981).

20. Matsubu, J. C. et al. Adsorbate-mediated strong metal-support interactions in oxide-supported Rh catalysts. Nat. Chem. 9, 120-127 (2017).

21. Green, I. X., Tang, W., Neurock, M. \& Yates, J. T. Spectroscopic observation of dual catalytic sites during oxidation of $\mathrm{CO}$ on a $\mathrm{Au} / \mathrm{TiO}_{2}$ catalyst. Science 333, 736-739 (2011).

22. Haruta, M., Kobayashi, T., Sano, H. \& Yamada, N. Novel gold catalysts for the oxidation of carbon monoxide at a temperature far below $0^{\circ} \mathrm{C}$. Chem. Lett. 16 405-408 (1987)

23. Ye, R., Zhao, J., Wickemeyer, B. B., Toste, F. D. \& Somorjai, G. A. Foundations and strategies of the construction of hybrid catalysts for optimized performances. Nat. Catal. 1, 318-325 (2018).

24. Gross, E., Liu, J. H.-C., Toste, F. D. \& Somorjai, G. A. Control of selectivity in heterogeneous catalysis by tuning nanoparticle properties and reactor residence time. Nat. Chem. 4, 947-952 (2012).

25. Lee, I., Delbecq, F., Morales, R., Albiter, M. A. \& Zaera, F. Tuning selectivity in catalysis by controlling particle shape. Nat. Mater. 8, 132-138 (2009).

26. Wittstock, A., Zielasek, V., Biener, J., Friend, C. \& Bäumer, M. Nanoporous gold catalysts for selective gas-phase oxidative coupling of methanol at low temperature. Science 327, 319-322 (2010).

27. Eren, B. et al. Structure of the clean and oxygen-covered $\mathrm{Cu}(100)$ surface at room temperature in the presence of methanol vapor in the 10-200 mTorr pressure range. J. Phys. Chem. B 122, 548-554 (2017).

28. Zugic, B. et al. Dynamic restructuring drives catalytic activity on nanoporous gold-silver alloy catalysts. Nat. Mater. 16, 558-564 (2017).

29. Wang, $\mathrm{H}$. et al. Influence of size-induced oxidation state of platinum nanoparticles on selectivity and activity in catalytic methanol oxidation in the gas phase. Nano Lett. 13, 2976-2979 (2013).

30. Lee, S. W. et al. Intrinsic relation between hot electron flux and catalytic selectivity during methanol oxidation. ACS Catal. 9, 8424-8432 (2019).

31. Chen, Z. et al. Understanding the dual active sites of the $\mathrm{FeO} / \mathrm{Pt}$ (111) interface and reaction kinetics: density functional theory study on methanol oxidation to formaldehyde. ACS Catal. 7, 4281-4290 (2017).

32. Farnesi Camellone, M. et al. Molecular understanding of reactivity and selectivity for methanol oxidation at the $\mathrm{Au} / \mathrm{TiO}_{2}$ interface. Angew. Chem. Int. Ed. 52, 5780-5784 (2013).

33. Contreras, A., Yan, X.-M., Kwon, S., Bokor, J. \& Somorjai, G. Catalytic CO oxidation reaction studies on lithographically fabricated platinum nanowire arrays with different oxide supports. Catal. Lett. 111, 5-13 (2006).

34. Contreras, A., Grunes, J., Yan, X.-M., Liddle, A. \& Somorjai, G. Fabrication of 2-dimensional platinum nanocatalyst arrays by electron beam lithography: ethylene hydrogenation and CO-poisoning reaction studies. Top. Catal. 39, 123-129 (2006).

35. Kim, J. M. et al. Eliminating the trade-off between the throughput and pattern quality of sub-15 nm directed self-assembly via warm solvent annealing. $A d v$. Funct. Mater. 25, 306-315 (2015). 
36. Jung, Y. S. \& Ross, C. A. Orientation-controlled self-assembled nanolithography using a polystyrene-polydimethylsiloxane block copolymer. Nano Lett. 7, 2046-2050 (2007).

37. Goddeti, K. C., Lee, H., Jeon, B. \& Park, J. Y. Enhancing hot electron collection with nanotube-based three-dimensional catalytic nanodiode under hydrogen oxidation. Chem. Commun. 54, 8968-8971 (2018).

38. Jeon, B., Lee, H., Goddeti, K. C. \& Park, J. Y. Hot electron transport on threedimensional $\mathrm{Pt} /$ mesoporous $\mathrm{TiO}_{2}$ Schottky nanodiodes. ACS Appl. Mater. Interfaces 11, 15152-15159 (2019).

39. Park, J. Y., Renzas, J., Hsu, B. B. \& Somorjai, G. A. Interfacial and chemical properties of $\mathrm{Pt} / \mathrm{TiO}_{2}, \mathrm{Pd} / \mathrm{TiO}_{2}$, and $\mathrm{Pt} / \mathrm{GaN}$ catalytic nanodiodes influencing hot electron flow. J. Phys. Chem. C 111, 15331-15336 (2007).

40. Park, J. Y., Lee, H., Renzas, J. R., Zhang, Y. \& Somorjai, G. A. Probing hot electron flow generated on Pt nanoparticles with $\mathrm{Au} / \mathrm{TiO}_{2}$ Schottky diodes during catalytic CO oxidation. Nano Lett. 8, 2388-2392 (2008).

41. Lee, $\mathrm{H}$. et al. Graphene-semiconductor catalytic nanodiodes for quantitative detection of hot electrons induced by a chemical reaction. Nano Lett. 16, 1650-1656 (2016).

42. Hervier, A., Baker, L. R., Komvopoulos, K. \& Somorjai, G. A. Titanium oxide/ platinum catalysis: charge transfer from a titanium oxide support controls activity and selectivity in methanol oxidation on platinum. J. Phys. Chem. C 115, 22960-22964 (2011).

43. Yoon, S. et al. Specific metal-support interactions between nanoparticle layers for catalysts with enhanced methanol oxidation activity. ACS Catal. 8, 5394-5398 (2018).

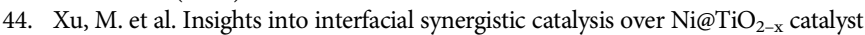
toward water-gas shift reaction. J. Am. Chem. Soc. 140, 11241-11251 (2018).

45. $\mathrm{Xu}, \mathrm{M}$. et al. $\mathrm{TiO}_{2-\mathrm{x}}$-modified $\mathrm{Ni}$ nanocatalyst with tunable metal-support interaction for water-gas shift reaction. ACS Catal. 7, 7600-7609 (2017).

46. Liu, N. et al. $\mathrm{Au}^{\delta-}-\mathrm{O}_{\mathrm{v}}-\mathrm{Ti}^{3+}$ interfacial site: catalytic active center toward lowtemperature water gas shift reaction. ACS Catal. 9, 2707-2717 (2019).

47. Hervier, A., Renzas, J. R., Park, J. Y. \& Somorjai, G. A. Hydrogen oxidationdriven hot electron flow detected by catalytic nanodiodes. Nano Lett. 9 3930-3933 (2009).

48. Lee, $\mathrm{H}$. et al. Enhanced hot electron generation by inverse metal-oxide interfaces on catalytic nanodiode. Faraday Dicuss. 214, 353-364 (2019).

49. Lee, $\mathrm{H}$. et al. Boosting hot electron flux and catalytic activity at metal-oxide interfaces of PtCo bimetallic nanoparticles. Nat. Commun. 9, 2235 (2018).

50. An, K. et al. Enhanced CO oxidation rates at the interface of mesoporous oxides and Pt nanoparticles. J. Am. Chem. Soc. 135, 16689-16696 (2013).

51. Baker, L. R. et al. Furfuraldehyde hydrogenation on titanium oxide-supported platinum nanoparticles studied by sum frequency generation vibrational spectroscopy: acid-base catalysis explains the molecular origin of strong metal-support interactions. J. Am. Chem. Soc. 134, 14208-14216 (2012).

52. Hanukovich, S., Dang, A. \& Christopher, P. Influence of metal oxide support acid sites on $\mathrm{Cu}$-catalyzed nonoxidative dehydrogenation of ethanol to acetaldehyde. ACS Catal. 9, 3537-3550 (2019).

53. Yang, Z. -Y., Wojtaszek-Gurdak, A., Yang, C. -M. \& Ziolek, M. Enhancement of selectivity in methanol oxidation over copper containing SBA-15 by doping with boron species. Catal. Today 356, 122-131 (2020).

54. Bunluesin, T., Putna, E. \& Gorte, R. A comparison of CO oxidation on ceriasupported Pt, Pd, and Rh. Catal. Lett. 41, 1-5 (1996).

55. Lee, S. W., Song, J. T., Kim, J., Oh, J. \& Park, J. Y. Enhanced catalytic activity for $\mathrm{CO}$ oxidation by the metal-oxide perimeter of $\mathrm{TiO}_{2} /$ nanostructured $\mathrm{Au}$ inverse catalysts. Nanoscale 10, 3911-3917 (2018).

56. Qadir, K. et al. Tailoring metal-oxide interfaces of inverse catalysts of $\mathrm{TiO}_{2} /$ nanoporous-Au under hydrogen oxidation. Chem. Commun. 51, 9620-9623 (2015).

57. Kennedy, G., Melaet, Grm, Han, H.-L., Ralston, W. T. \& Somorjai, G. A. In situ spectroscopic investigation into the active sites for crotonaldehyde hydrogenation at the Pt nanoparticle- $\mathrm{Co}_{3} \mathrm{O}_{4}$ interface. ACS Catal. 6 7140-7147 (2016).

58. Xu, B., Haubrich, J., Baker, T. A., Kaxiras, E. \& Friend, C. M. Theoretical study of O-assisted selective coupling of methanol on Au (111). J. Phys. Chem. C. 115, 3703-3708 (2011)

59. Nørskov, J. K., Studt, F., Abild-Pedersen, F. \& Bligaard, T. Fundamental Concepts in Heterogeneous Catalysis (Wiley, 2014).
60. Kim, J. et al. Adsorbate-driven reactive interfacial $\mathrm{Pt}-\mathrm{NiO}_{1-\mathrm{x}}$ nanostructure formation on the $\mathrm{Pt}_{3} \mathrm{Ni}$ (111) alloy surface. Sci. Adv. 4, eaat3151 (2018).

61. Kresse, G. \& Furthmüller, J. Efficiency of ab-initio total energy calculations for metals and semiconductors using a plane-wave basis set. Comput. Mater. Sci. 6, 15-50 (1996).

62. Perdew, J. P., Burke, K. \& Ernzerhof, M. Generalized gradient approximation made simple. Phys. Rev. Lett. 77, 3865 (1996).

63. Blöchl, P. E. Projector augmented-wave method. Phys. Rev. B 50, 17953 (1994).

64. Dudarev, S., Botton, G., Savrasov, S., Humphreys, C. \& Sutton, A. Electronenergy-loss spectra and the structural stability of nickel oxide: An LSDA + U study. Phys. Rev. B 57, 1505 (1998).

65. Henkelman, G., Uberuaga, B. P. \& Jónsson, H. A climbing image nudged elastic band method for finding saddle points and minimum energy paths. $J$. Chem. Phys. 113, 9901-9904 (2000).

66. Tang, W., Sanville, E. \& Henkelman, G. A grid-based Bader analysis algorithm without lattice bias. J. Phys. Condens. Matter 21, 084204 (2009).

\section{Acknowledgements}

This work was supported by the Institute for Basic Science (IBS) [IBS-R004]. Y.J. acknowledges support through the National Research Foundation of Korea from the Korean Government (NRF-2019M3D3A1A01069099 \& 2016M3D1A1021147).

\section{Author contributions}

S.W.L. and J.Y.P. planned and designed the experiments. S.W.L. performed the central measurements and analysis. S.W.L. and H.L. fabricated the nanodevices and carried out the chemicurrent and catalytic activity measurements. W.P. and Y.J. performed the DFT calculations. J.K., G.R.L., and Y.S.J. fabricated the nanowire-based diode. All authors discussed the results and contributed to the manuscript.

\section{Competing interests}

The authors declare no competing interests.

\section{Additional information}

Supplementary information is available for this paper at https://doi.org/10.1038/s41467 020-20293-y.

Correspondence and requests for materials should be addressed to Y.J., Y.S.J. or J.Y.P.

Peer review information Nature Communications thanks Bin Wang and the other, anonymous, reviewer(s) for their contribution to the peer review of this work. Peer reviewer reports are available.

Reprints and permission information is available at http://www.nature.com/reprints

Publisher's note Springer Nature remains neutral with regard to jurisdictional claims in published maps and institutional affiliations.

Open Access This article is licensed under a Creative Commons Attribution 4.0 International License, which permits use, sharing, adaptation, distribution and reproduction in any medium or format, as long as you give appropriate credit to the original author(s) and the source, provide a link to the Creative Commons license, and indicate if changes were made. The images or other third party material in this article are included in the article's Creative Commons license, unless indicated otherwise in a credit line to the material. If material is not included in the article's Creative Commons license and your intended use is not permitted by statutory regulation or exceeds the permitted use, you will need to obtain permission directly from the copyright holder. To view a copy of this license, visit http://creativecommons.org/ licenses/by/4.0/

(C) The Author(s) 2021 